\title{
Cybernetics and Simulacra: The Hyperreality of Augmented Reality Games
}

\author{
Rhoderick V. Nuncio \\ Johannah Mari B. Felicilda
}

\begin{abstract}
The paper explores and critically interrogates the proliferation of online games as showcased in the rise of augmented reality (AR) games such as Harry Potter: Wizards Unite and the like using the concepts of "cybernetics" and "simulacra." These are two powerful notions evident in contemporary times that when combined can be used to unmask the inner workings of AR games and to critique $21^{\text {st }}$ century's overdependency on and overdetermination of technology. The first task of the paper is to analytically decode AR game using the idea of cybernetics and John Cormack's creative ecosystem. Side by side this immanent exposition is the unmasking of such creative ecosystem that brings to light Jean Baudrillard's idea of hyperreality. The second task is to critically examine the philosophical underpinnings of AR that reiterates a transcendent critique by showing its implications and significations towards understanding the heterogeneity of human and machine interplay within the context of digital capitalism.
\end{abstract}

Keywords: cybernetics, simulacra, Jean Baudrillard, augmented reality games, digital capitalism

By the late twentieth century, our time, a mythic time, we are all chimeras, theorized and fabricated hybrids of machine and organism; in short, we are cyborgs. The cyborg is our ontology; it gives us our politics. The cyborg is a condensed image of both imagination and material reality, the two joined centers structuring any possibility of historical transformation.

- Donna Haraway ${ }^{1}$

1 "A Cyborg Manifesto: Science, Technology, and Socialist-Feminism in the Late Twentieth Century," in Simians, Cyborgs and Women: The Reinvention of Nature (New York: Routledge, 1991), 149-81.

(c) 2021 Rhoderick V. Nuncio and Johannah Mari B. Felicilda https://www.kritike.org/journal/issue 29/nuncio\&felicilda december2021.pdf

ISSN 1908-7330

(c) $\mathrm{BY}-\mathrm{NC}-\mathrm{ND}$ 


\section{CYBERNETICS AND SIMULACRA}

7 he $21^{\text {st }}$ century is more likely this: we engage in visual consumption, and we are entering a new paradigm of virtual reality of humanmachine blended interactions. The visual has the power to become virtual or hyperreal as what it is now through graphic designs, 3D and 4D digital arts, algorithmic computer art, photo-video filtered and edited effects, immersive games, and augmented reality (AR) environments. Undeniably, the proliferation of images, copies of the images and simulations through virtual and AR interface embedded in online games captured, displayed, and executed in many digital platforms has reconstituted how we understand ourselves and our daily reality in the age of information and communication technology. It nonetheless poses a rethinking of sort to situate our position whether our encounter with these simulations and simulacra in a Baudrillardian sense are enacting a new world order ushered in by the Fourth Industrial Revolution or the rise of digital capitalism.

In situating the claim using immanent analysis and critique of $A R$, an illustrative sample is then presented by probing the cybernetic functions of AR games, which in this case centers on Harry Potter: Wizards Unite. In doing so, a descriptive analysis becomes imperative using Jon McCormack's creative ecosystem model $^{2}$ to unearth the narrative code of the game. Then, a critique is presented using Jean Baudrillard's semio-linguistic theory to expose the transition of the narrative code as the ideological code enmeshed with the rhetoric of digital age. This paper also aims to inquire on the philosophical import and underpinnings of AR as an encompassing notion in understanding online games and the rise of digital capitalism. A critical interrogation shall focus on analyzing the present condition as postmodern tendencies reminiscent of late capitalism that allows the propagation and dominance of digital capitalism.

\section{Defining Cybernetics and Augmented Reality Games}

Before we proceed to understanding the inner workings of AR games using Harry Potter: Wizards Unite (henceforth, Wizards Unite) as our specimen for analysis, let us be clear first by what we mean by cybernetics and AR in this context.

Cybernetics is an amalgam of theories on system flow, control of information and communication as Norbert Wiener, ${ }^{3}$ an American mathematician and philosopher, explicates the study of how organic, human, machine and information build analogous system of feedback and selforganization. Cybernetics-coined from the Greek word for "steersman,"

\footnotetext{
2 Jon McCormack, "Creative Ecosystems," in Computers and Creativity, 51 (1998).

${ }^{3}$ See Norbert Wiener, Cybernetics: Or, Control and Communication in the Animal and the Machine, 2nd ed. (Cambridge: The MIT Press, 2019).
}

(c) 2021 Rhoderick V. Nuncio and Johannah Mari B. Felicilda https://www.kritike.org/journal/issue 29/nuncio\&felicilda december2021.pdf ISSN 1908-7330

(c) BY-NC-ND 
signaled three powerful actors: information, control, and communicationnow operate jointly to bring about unprecedented synthesis of the organic and the mechanic. ${ }^{4}$ The point of this definition of relationship maintains that there is a continuity of these two modes of contact between the organic and mechanic or man and machine within one loop of engagement. Hence, the relationship between computers and humans is the basic example of cybernetics. Simply put, cybernetic is a closed system by which humanmachine interaction takes place. Machines become an extended apparatus of humans to perform certain tasks like in manufacturing cars using assemblyline machinery, in operating patients using medical equipment, and in exploring the cosmos using the Hubble telescope, to name a few. The next level of cybernetic interaction is the "blending" of human-machine encounter. This is where AR games or its variations come in. Wiener explains that cybernetics blurs the distinction between animate/inanimate, man/machine. ${ }^{5}$ Henceforth, this is not just simply an extension of the limbs and body parts of human beings with the help of machines, software, and devices to do difficult and complex tasks. A "digital environment" is embedded to alter or situate the perception of humans within a feedback loop system designed in simulated environments just in the case of AR games. This digital environment is interpreted here as the creative ecosystem of the cybernetic relationship between online players (human agency) and the machine (device, gadget) for online games.

In this context, it is paramount to discuss the nature of $A R$, specifically AR games. AR is part of an entire gamut of extended reality technology $(X R)^{6}$, which refers to all combined real-and-virtual environments and human-machine interactions generated by computer technology and wearables. Under this umbrella term of XR, we have AR, virtual reality (VR), and mixed reality (MR), each of which offers varying degrees of experiencing the virtual world. Through VR technology, the user is introduced to a completely computer-simulated reality which can be accessed with the use of VR headsets (e.g., Oculus Rift, Oculus Quest, HTC Vive Cosmos). The ideal VR experience takes over the five senses of the user to fully immerse them within the created imaginary world. Although most VR applications focus on engaging the user through realistic visuals and sounds. The user is also able to interact with the objects and people within the virtual world using handheld consoles. If VR and AR are polar opposites, MR can be considered as its

\footnotetext{
${ }^{4}$ Katherine Hayles, How We Became Posthuman: Virtual Bodies in Cybernetics, Literature, and Informatics (Chicago: University of Chicago Press, 1999), 8.

${ }^{5}$ Ibid., 84.

${ }^{6}$ North of 41, “What Really Is the Difference between AR / MR / VR / XR?," in Medium (20 March 2018), <https://medium.com/@northof41/what-really-is-the-difference-between-armr-vr-xr-35bed1da1a4e>.
}

(c) 2021 Rhoderick V. Nuncio and Johannah Mari B. Felicilda https://www.kritike.org/journal/issue 29/nuncio\&felicilda december2021.pdf ISSN 1908-7330 


\section{CYBERNETICS AND SIMULACRA}

meeting point. MR is sometimes referred to as hybrid reality because it is the merging of real and virtual worlds to produce new environments and visualizations where physical and digital objects coexist and interact in real time. ${ }^{1}$ MR technology superimposes virtual elements onto real objects and allows the user to interact with them in real time. This can be experienced through specialized MR headsets (e.g., Microsoft HoloLens).

AR games, such as Wizards Unite, offers the user an enhanced version of the real world. AR technology is a live, direct, or indirect view of a physical, real-world environment whose elements are augmented (or supplemented) by computer-generated sensory input such as sound, video, graphics, or GPS data. ${ }^{7}$ Compared to other XR technology, AR is the most accessible because the most popular medium used by developers are smart phones. By using phone cameras, we become privy to various experiences and elements unseen through the naked eye.

The succeeding discussion of Wizards Unite is premised on Jon McCormack's creative ecosystem as the underlying cybernetic presuppositions regarding player and game interaction or human-machine interplay.

\section{The Cybernetic Simulacra of Harry Potter: Wizards Unite}

A closer analysis must lay down first the idea of simulations and simulacra. Jean Baudrillard proclaims the precession of simulacra in which the notion that models, images, maps, or pictures precede "reality" or reference to a reality as the significant characteristic when we situate this analysis within the context of AR games.

Abstraction today is no longer that of the map, the double, the mirror or the concept. Simulation is no longer that of a territory, a referential being or a substance. It is the generation by models of a real without origin or reality: a hyperreal. The territory no longer precedes the map, nor survives it. Henceforth, it is the map that precedes the territory - precession of simulacra.... ${ }^{8}$

As mentioned earlier, compared to other XR technology, AR is the most accessible because the most popular medium used by developers are smart phones. Our phone cameras allow us to experiences elements unseen

\footnotetext{
${ }^{7}$ Ibid.

${ }^{8}$ Jean Baudrillard, "Simulacra and Simulations," in Jean Baudrillard: Selected Writings, ed. by Mark Poster (Stanford; Stanford University Press, 1988).

(c) 2021 Rhoderick V. Nuncio and Johannah Mari B. Felicilda https://www.kritike.org/journal/issue 29/nuncio\&felicilda december2021.pdf ISSN 1908-7330

(c) ) BY-NC-ND
} 
by the naked eye. AR gaming is a simulation in that it situates an ambiguous experience by placing the user in a world in limbo, neither entirely virtual nor real, and neither fully connected nor disconnected. The user also assumes a character or a persona while playing the game-an upgraded version of themselves, so to speak. Typically, in online gaming, the user subverts their physical environment for the game requires their undivided attention. Their eyes are glued to the screen because it is their only access to that virtual world. Once you connect to the internet, you become disconnected to the real world. However, in AR gaming, it actively reminds you that you are traversing the real world, albeit enhanced by the technology you are holding in your hand. It is true that you cannot play without being connected to the internet but at the same time you also cannot play without being "disconnected" to explore the real world.

This in-between state that requires both technology and human ingenuity can be described as a creative ecosystem in which dynamic components interact with the environment. In the context of AR gaming, the virtual elements are superimposed into and influenced by real-world terrains. This cybernetic interaction, mimics a biological ecosystem in the following sense:

In the broadest terms, the modern concept of an ecosystem suggests a community of connected, but disparate components interacting within an environment. This interaction involves dependency relationships leading to feedback loops of causality. The ecosystem has the ability to self-organise, to dynamically change and adapt in the face of perturbation. It has redundancy and the ability to self-repair. ${ }^{9}$

From this definition of a biological ecosystem, McCormack identifies seven properties pertinent to a creative ecosystem model ${ }^{10}$ which will be used in analyzing the cybernetic features of the AR gaming experience through Wizards Unite.

First are the "components and their environment" which constitute the ecosystem. In the context of AR gaming, this includes the virtual world of the game (its cast of characters, gameplay, and other similar elements) as well as the real-world environment that it interacts with.

Second is the "dynamic system" which enables the ecosystem to temporarily adapt and change in response to internal and external conditions.

${ }^{9}$ McCormack, “Creative Ecosystems,” 45.

${ }^{10} \mathrm{Ibid} ., 51$.

(C) 2021 Rhoderick V. Nuncio and Johannah Mari B. Felicilda https://www.kritike.org/journal/issue 29/nuncio\&felicilda december2021.pdf ISSN 1908-7330 


\section{CYBERNETICS AND SIMULACRA}

This includes the actual gameplay in which the player weighs the rewards and consequences of the challenges within the game.

Third is "self-observation" which provides a link between component action and environment. In relation to the previous property, this includes how the environment affects the player while they are immersed in gaming.

Fourth is "self-modification" which allows a component to adjust its behavior within the system. In gaming, these are measures taken by the player to advance further and more efficiently in the game.

Fifth is "interaction" which means components must interact with each other and their environment to give rise to emergent behaviors of the system as a whole. Gaming as an activity sometimes involves other people, their interaction with each other vis-à-vis the virtual environment adds to the entirety of the experience.

Sixth is "feedback loops" which provides pathways of control, regulation, and modification of the ecosystem. Games are constantly updated by developers guided by their own vision and the demands of their market. Through this, the creative ecosystem evolves and develops.

Finally, seventh is "evolution" which allows long-term change, learning, and adaptation. Much like the actual study of evolution, the changes made in the game can be tracked and its trajectory can be predicted.

\section{Components, Environment, and Dynamic System vis-à-vis Hyperreality}

The creative ecosystem is thus not complete without firming up the reason behind the popularity of online games. This ecosystem that refers and builds up the digital environment wherein human-game interface occurs is hyperreality itself. At the outset, a dual environment is present - the real vs. the virtual. A player's social identity is defined by his/her social roles and existential situation. He could be a college student struggling to cope with the recent pandemic. She could be an ordinary teenager, curious about how Harry Potter, her beloved childhood hero, could be played virtually and how playing this game could bring her closer to her friends online. The hyperreal world of the game gives that sense of respite or refuge against the problematic nature of lived existence. Baudrillard critically lays down a player's point of departure once he/she enters the game:

1. It is the reflection of a basic reality.

2. It masks and perverts a basic reality.

3. It masks the absence of a basic reality.

(c) 2021 Rhoderick V. Nuncio and Johannah Mari B. Felicilda https://www.kritike.org/journal/issue 29/nuncio\&felicilda december2021.pdf ISSN 1908-7330

(c) $)$ BY-NC-ND 


\section{It bears no relation to any reality whatever: it is its own pure simulacrum. ${ }^{11}$}

Reflection of basic reality is Baudrillard's idea of representation. We know for a fact that people as gamers using different user accounts or gamers posturing as avatars or as Harry Potter's magical characters are real people. In playing Wizards Unite, the user is given the chance to become a wizard or a witch. This game, released in 2019, is based on the best-selling series of children's novels of J.K. Rowling. The first task the users do is to don the persona of their character in the game. For Wizards Unite, this means becoming a wizard in the Muggle world.12 Being inconspicuous is needed while playing the game so as not to attract unnecessary attention from the people around you. Becoming a character and merging with this virtual world also means that your objectives are aligned with the game and achieving them bears more weight than it would in the real world. Unbeknownst to us will be the character's/avatar's actual social standing since what we can grasp are their virtual appearances and the objects and powers they possess in the game that signify their rank or level in the game. Genesko succinctly applies Baudrillard's production of differences of personality, which can be applied in the way gamers represent their identity inside the game:

$[P]$ roduction of differences that allegedly allow individuals to be themselves, to have their own style and personality, simultaneously erase singular differences between persons for the sake of replacing them with signs of difference, more and more subtly and minutely defined, in conformity with abstract, artificial models. The consequence is that to be yourself under the terms of consumer society is to be what you are not (that is, they are embedded in a structural theory of value). ${ }^{13}$

\footnotetext{
${ }^{11}$ Baudrillard, "Simulacra and Simulations."

${ }^{12}$ In the story of Harry Potter, the Muggle world is the nonmagical world.

${ }^{13}$ Gary Genesko, "Jean Baudrillard's Contributions to Semiotic and Structural Studies," in International Journal of Baudrillard Studies, 4 (2007).

(c) 2021 Rhoderick V. Nuncio and Johannah Mari B. Felicilda https://www.kritike.org/journal/issue 29/nuncio\&felicilda december2021.pdf ISSN 1908-7330 


\section{CYBERNETICS AND SIMULACRA}

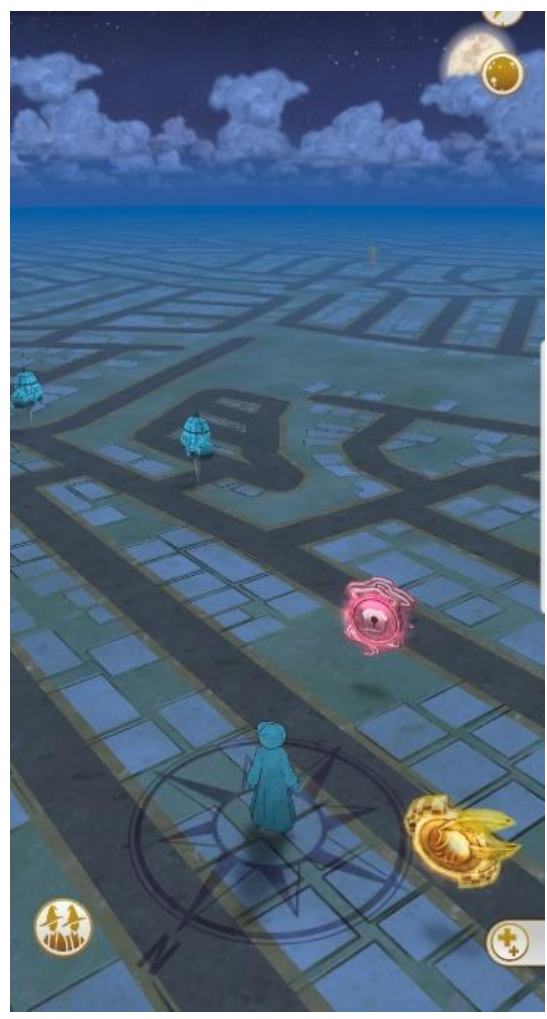

Figure 1. Screenshot of the game interface of Wizards Unite.
This structural theory of value is intertwined with the signification that imbues simulation of differences of characters depending on how you play the game and how you accomplish the tasks to achieve certain levels of hierarchy. AR adventure games can be thought of as actual adventures because it involves actual exploration and consecutive challenges. To advance in the game, you must walk around and explore your surroundings. You find yourself going to places that you have never been to before because there is an object that you want to collect or an adversary you wish to defeat. The fact that physical effort needs to be exerted to accomplish tasks and challenges makes the achievement more tangible. As your energy depletes in the game, so it also does in real life. With every success, you feel more empowered and convinced that you can advance, motivating you to keep playing.

Similarly, this represents how people in actual or real society move up the social or organizational ladder. Competition or beating others out as you perform takes a similar turn in all online games. All games point to a basic reality of a competition that is waged against an enemy or a challenge to be accomplished. Furthermore, the game is replete with references to castles, suitcases, herbs, ingredients, objects, animals, and the like that correspond or resemble one way or the other actual referents. The general interface of the game is fairly simple with its blank map aesthetic, quite similar to a GPS interface (Figure 1). This is strategic: considering that you must walk through the streets to advance in the game, it would be very dangerous for you to be distracted by the visuals on your phone. Hence, the interface allows users to focus on their actual surroundings, especially if it is crowded and there are vehicles passing by. Additionally, when you open the app on your phone, you are greeted with a warning to be always wary of your surroundings. Similar pop-up messages come by occasionally, as you are playing the game (Figure 2). 

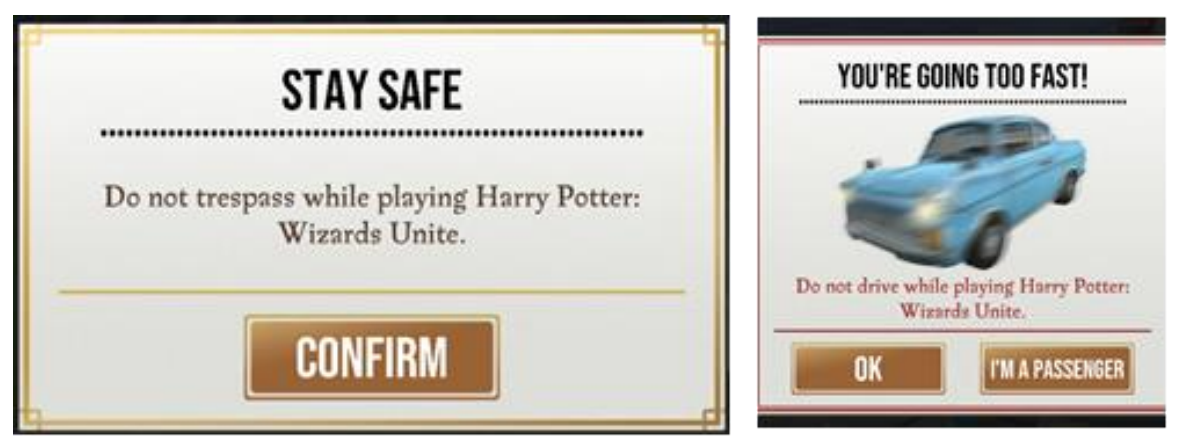

Figure 2. Warning pop-ups in Wizards Unite.

In exploring the game, you may also visit Inns, Greenhouses, and other landmarks. ${ }^{14}$ In order to emphasize the theme of "hidden magic," the game's map mirrors landmarks in real life (Figure 3). Gardens and plant vendors in the real world are Greenhouses; hotels and restaurants are Inns. This reflection of "basic" reality is the springboard for online game engagement, which in a way will shift toward subverting such basic reality into a code-a signification of multiple signs - that rests on the game's narrative.

This brings us to Baudrillard's second characteristic that hyperreality masks and perverts basic reality. This reality rests on a fantastical narrative, which is the crux of the game that pivots on slaying or defeating supernatural beings with immense magical powers and situating the entire virtual experience in a simulated environment like an enchanted forest, alien planets, otherworldly dimensions, and the like. Hence, it is a general code that purports acceptance and obedience, in short, a
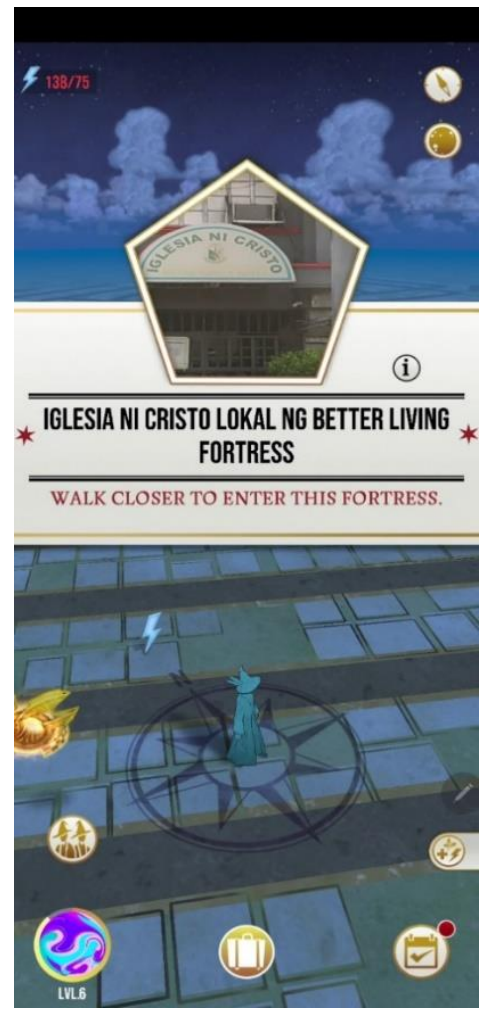

Figure 3. Screenshot of a real-life landmark found in Wizards Unite. suspended disbelief. Baudrillard proclaims that the "collective function of advertising is to convert us all to the code."15 In a simulated way, this is the

\footnotetext{
${ }^{14}$ The Inns provide food which would replenish your energy. The Greenhouses provide potion ingredients.

${ }^{15}$ Jean Baudrillard, "System of Objects," in Jean Baudrillard: Selected Writings, ed. by Mark Poster (California: Stanford University Press, 1988), 19.
} 


\section{CYBERNETICS AND SIMULACRA}

narrative code of the game and the "advertising" which Baudrillard calls forth as an enticement to provoke nostalgic feeling of mass culture that can be embedded from books and films to graphic novels enculturated as a game. Advertising then becomes a pre-game scenario, but in totality (as the game points to a constellation of signs as fiction, fantasy, and as product of previous successes of mass culture industry) an advertisement then becomes magically transformed as the game itself. Fiction as it is (i.e., Harry Potter as a book series $^{16}$ and as a blockbuster cult movie), the transition and transmission of such into a digital edition as AR games is an important aspect of the lure of the narrative as code. The pages of fiction are filled with daring adventures into far-off lands or distant timelines that introduce us to unfamiliar places and creatures. These books fueled our imagination and revved our desire to become like the heroes we have come to love. In children, these dreams were encouraged and admired but all at once shattered at the eve of puberty. However, these desires do not simply vanish but merely tucked away and unearthed given the opportunity to indulge in its fruition. These wild childhood dreams were unreachable until recent technological advances made it possible through the creation of simulations or virtual words, like in AR games. Baudrillard then highlights these acts of codification and recodification (from books and films to online games) to strengthen his arguments about consumption as the "virtual totality of all objects and messages presently constituted in a more or less coherent discourse. Consumption, in so far as it is meaningful, is a systematic act of the manipulation of signs." 17

Into the realm of the game, the narrative starts off with a mysterious event called "The Calamity" that has caused various magical artefacts, creatures, people, and even memories to appear in the Muggle world. This threatens the secrecy of the Wizarding World which is something the player must protect. The player is tasked by Hermione Granger, who is now head of the Statute of Secrecy Task Force, to search for "Foundables" on behalf of the Ministry of Magic. The objective of the game is to find these objects and release them from their Confoundable Charms. More information is revealed about the cause of The Calamity with every Foundable collected. Thus, we see here the conversion pattern of objects in the game as the manipulation of signs through masking and perversion of meanings of objects as without or devoid of reference. Because the third aspect of hyperreality in a Baudrillardian sense is the absence of a basic reality, the only reality that is given is the narrative code of the game-which urges players to play it! The game itself becomes the point of departure and announces a suspended

\footnotetext{
16 These novels were a huge part of many of our childhoods. The game continues long after where Rowling left off, years after the death of Voldemort at the Battle at Hogwarts.

${ }^{17}$ Baudrillard, "System of Objects," 21-22.
}

(c) 2021 Rhoderick V. Nuncio and Johannah Mari B. Felicilda https://www.kritike.org/journal/issue 29/nuncio\&felicilda december2021.pdf ISSN 1908-7330

(c) BY-NC-ND 
disbelief to accept what is perceived, observed, and interacted upon by the players. Hence these relations of objects (visible, manipulatable, and interactive in the game) become meaningful only within the context of the game, within the situatedness of the narrative and within an AR that is in itself a hyperreality.

The conversion of the object to a systematized status of signs entails a concomitant modification in the human relation, which becomes a relation of consumption. That is to say, human relations tend to be consumed (consommer) (in the double sense of the word: to be "fulfilled," and to be "annulled") in and through objects, which become the necessary mediation and, rapidly, the substitutive sign, the alibi, of the relation. ${ }^{18}$

How do these relations of objects operate in the game? As mentioned, the game is premised on collecting the Foundables that are threatened to be exposed to the public, i.e., outside the magical world of Harry Potter. In searching for these Foundables, the player must physically walk and explore their immediate environment. Once you find a Foundable, you may release them from their binding by tracing a glyph on your phone (Figure 4). This is the game equivalent of performing magic or using a wand. The more accurate you trace the symbol, the stronger the effect. Your magical prowess also increases as you complete more training, or it can be increased for a limited time by drinking potions. In your search for Foundables, you will also encounter potion ingredients and energy bolts to help you advance. With every Foundable saved, the level of the player increases. Once Level 6 is unlocked, players are asked to choose between three professions: Auror, Professor, and Magizoologist. Each profession has a distinct multilevel Skill Tree the player must unlock. This is done through collecting Spell Books which are rewarded to the player through encounters with magical beings, by leveling up or completing challenges.

${ }^{18}$ Baudrillard, "System of Objects," 22.

(c) 2021 Rhoderick V. Nuncio and Johannah Mari B. Felicilda https://www.kritike.org/journal/issue 29/nuncio\&felicilda december2021.pdf ISSN 1908-7330 


\section{CYBERNETICS AND SIMULACRA}

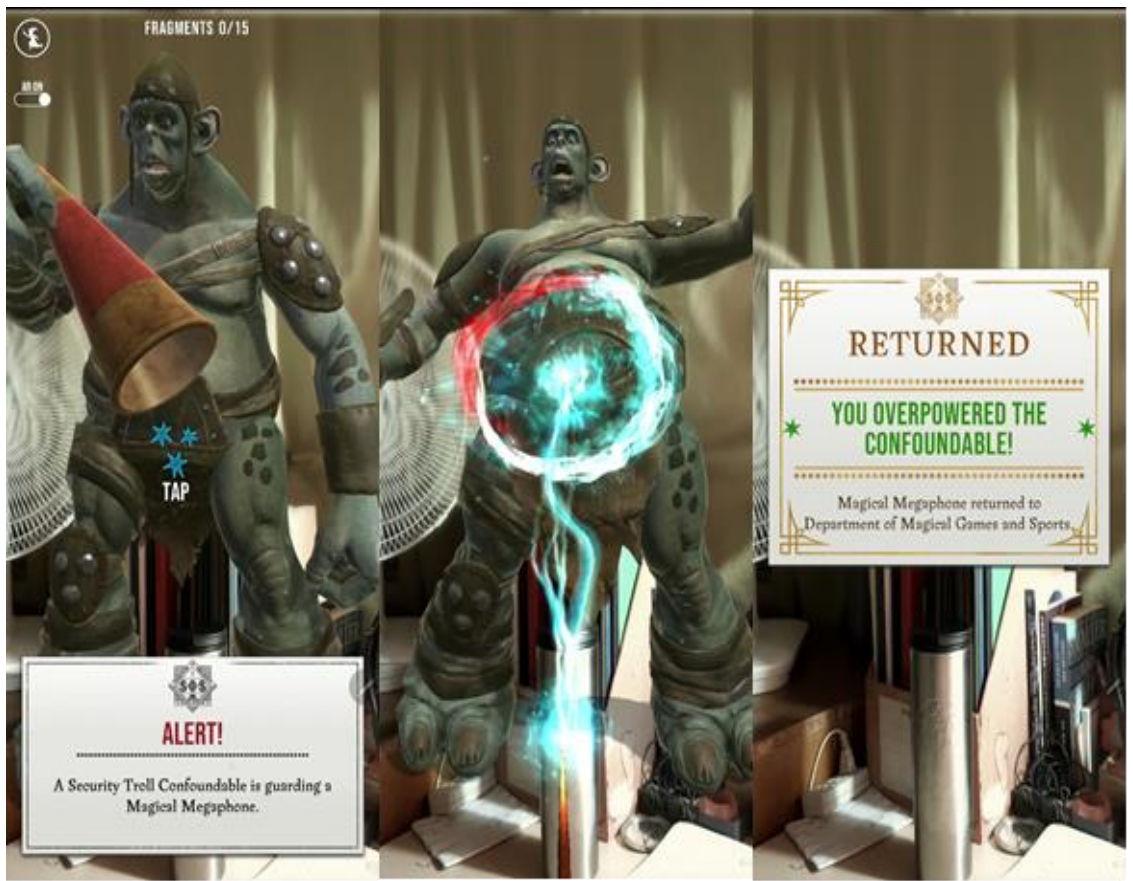

Figure 4. Sample gameplay transitions in Wizards Unite.

In games like Wizards Unite with an existing expansive lore, many of its users seek familiarity. In this particular game, the developers included memorable characters and events from the books, as well as new storylines that the users might enjoy. However, these are not immediately available to the users at the beginning of the game. The objects must be encountered and saved multiple times before it can even be included in the Registry. ${ }^{19}$ The player would then keep playing to unlock these objects, people, and stories. These interrelationships within the sign systems of the game constitute not the consumption of the objects-signs (Foundables, potions, wizards, spell books, etc.) but the consumption of relation itself invoking cybernetic loop of players and the game itself. This is where addiction to online games can be theoretically drawn. A player does not stop unless he/she completes the game. The game does not end unless human participants are completely immersed in the game. These two concomitant prerequisites echo the rationale why online or AR games are created or produced in the first place.

We can see that what is consumed are not objects but the relation itself-signified and absent, included and excluded at the same time-it is the idea of the relation that is consumed in the series of objects which manifests

${ }^{19}$ The Registry is an inventory of all the Foundables collected in the game.

(C) 2021 Rhoderick V. Nuncio and Johannah Mari B. Felicilda https://www.kritike.org/journal/issue 29/nuncio\&felicilda december2021.pdf ISSN 1908-7330 
it. This is no longer a lived relation: it is abstracted and annulled in an object-sign where it is consumed. At all levels, the status of the relation/object is orchestrated by the order of production...In order to be integrated it must be "personalized." 20

\section{Self-Observation, Self-Modification, and Interaction: Cyborg and Digital Clone}

The aim of a dynamic system of the game is conformity with the simulacrum. And this is encoded in three ways: (1) It is no more arbitrary than any other code. (2) The code is a form of socialization. (3) The code establishes, for the first time in history, a universal system of signs and interpretation..$^{21}$

The first one is the normalizing effects of online games as simulacrum, and this works seamlessly through the immersive power of online games. Immersion is vital in establishing flow in a user's experience. Flow is the holistic sensation of being fully immersed in an activity and enjoying the experience in the process. ${ }^{22}$ In order for flow to be established the user must willingly accept the premise and embrace the challenges of the game, a highly subjective experience that developers cannot fully predict. ${ }^{23}$ As such Baudrillard argues, "in order to become object of consumption, the object must become sign..." 24 In a way, the player is the object of consumption, and he/she is therefore must be transformed as a sign.

The initial reference of the self in the real world is part of this transformation and normalization. The reason why users are immersed in a game would depend on their own idiosyncrasies, and the influence of their contexts such as their pre-existing conditions and personal traits. Thus, immersion cannot be measured in terms of the media design or the intention of manufacturers; it is a subjective experience that can be measured only by the users. ${ }^{25}$ Immersion is internalized in the user. The game merely aids the imagination of the user; it does not dictate it. Accepting the context of the game and immersing yourself within in it is a conscious decision of the user.

\footnotetext{
${ }^{20}$ Baudrillard, “System of Objects," 22.

${ }^{21}$ Ibid., 19-20.

${ }^{22}$ Chun-Hsiung Lee, Hsiu-Sen Chiang, and Kuo-Lun Hsiao, "What Drives Stickiness in Location-Based AR Games? An Examination of Flow and Satisfaction," in Telematics and Informatics, 35 (2018).

${ }^{23}$ Donghee Shin, "How Does Immersion Work in Augmented Reality Games? A UserCentric View of Immersion and Engagement," in Information, Communication \& Society, 22 (2019): 1212-29, https://doi.org/10.1080/1369118X.2017.1411519.

${ }^{24}$ Baudrillard, "System of Objects," 20.

${ }^{25}$ Shin, “How Does Immersion Work in Augmented Reality Games?," 1213.
} 


\section{CYBERNETICS AND SIMULACRA}

To do this, the user creates or reconstructs a hybrid reality within themselves that accepts their own disposition and weaves it into the context of the game which extends into the real world as well.

The experience of being immersed in this creative ecosystem is modified by the internal conditions of the player, particularly their sense of imagination which enhances the simple graphics of the game. Furthermore, as the player unlocks more parts of the map, the ecosystem continues to grow. As the player's level increases and the map expands, the challenges become harder, and the enemies become more difficult to defeat. This dynamic system ensures that the game thrives. Towards this symbiotic process, the second reference of the self is its erasure. Signified as a player but absent as a being, which means his/her entire social being is not a referent or existing per se when immersion goes deeper in the digital experience. The player assumes a simulacrum. This is the fourth condition of hyperreality. The narrative code, the series of virtual objects in the game, the entire simulation of a digital environment are no longer lived relation but rather a simulacrum of the player's "digital presence" in the object-sign interplay. Personalization (digital presence, characterization, embeddedness in the narrative), therefore, is one's being and becoming rolled up in a singularity that is to be consumed and be consummated by the game. A simulacrum is only viable and feasible within the perceptive and immersive involvement of human beings integrated in the cybernetic loop and placed within the relations of objectssigns of the game. Without this component, hyperreality is nil.

Self-observation is the process by which players perceive their digital self onto the screen - into the hyperreality of the game - and at the same time, perform and function by assuming a digital self as virtually existent. This digital copy of the self is not independent nor self-reflective (like an automaton or a robot that has its own consciousness) apart from the "real" person acting as the player. It passes through a process of self-modification from "real" to "virtual" as explained above through digital personalization and embeddedness in the narrative code of the game. However, in its systematic and systemic flow from real to virtual and vice versa (when one unplugs from the game) we can derive how the self is transformed and normalized as a "cyborg" within the context of player-game or humanmachine interaction.

A cyborg, as defined by Donna Haraway, is a human-machine hybrid whose complexity and fluidity blurs and therefore challenges the essentialist dichotomies that limit our reality and existence. In this context, the user is a cyborg in the sense that their gadgets become an extension of their being which enables them to interact with a virtual world that augments their interpretation of reality. Therefore, in this context, the cyborg in the creative ecosystem also challenges the dichotomy between the virtual and the real.

(c) 2021 Rhoderick V. Nuncio and Johannah Mari B. Felicilda

https://www.kritike.org/journal/issue 29/nuncio\&felicilda december2021.pdf

ISSN 1908-7330

(c) $)$ BY-NC-ND 
Games are simulations because it obscures reality by immersing the individual in an imaginary or hyperreal environment. It is a manufactured world accessible only through technology and therefore, a virtual reality. However, in this context, the gamer is not a passive conduit of information that suspends their own agency when inside the virtual world. If we think of the individual as a cyborg in a symbiotic relationship with its creative ecosystem, in which their existence and continuity is dependent on each other, the line between virtual and real becomes blurred. It is true the virtual world is a pre-authored space, but the telepresence of the unique subject position of the gamer interpreting and interacting with the game parameters creates a novel experience - a unique cyber-reality. ${ }^{26}$ This cyber-reality is only possible through the active interaction and participation of the cyborg with the creative ecosystem. In other words, human agency and imagination is needed. The gamer/cyborg creates meaning and significations within the virtual world and enhances their own in the process, resulting in a creative ecosystem that is an amalgamation of the virtual and the real. It is not an illusion or a distorted reality but rather an enhanced version of it. Thus, as a matter of perspective from the observer's point of view, a cyborg is inherently signified to refer to being as a closure of duality (real-virtual self). But what about the "digital self" conceived as it is and interpreted within the context of its digital environment?

Baudrillard has his own interpretation about the "double" in his discourse about "cloning" which we can use to equate it with the digital self. This idea of the double is conjured as a phantasm:

[T] he imaginary power and wealth of the double - the one in which the strangeness and at the same time the intimacy of the subject to itself are played out...rests on its immateriality, on the fact that it is and remains a phantasm. Everyone can dream, and must have dreamed his whole life, of a perfect duplication or multiplication of his being, but such copies only have the power of dreams, and are destroyed when one attempts to force the dream into the real. ${ }^{27}$

Indeed, the double of the self in the way it is constructed is an offshoot of one's imagination and fantasy. In the digital world every aspect of our biology, appearance, and identity can be made better or more

${ }^{26}$ David Owen, "Cyber Narrative and the Gaming Cyborg," Journal of Gaming \& Virtual Worlds, 6 (2014), 210.

27 Jean Baudrillard, "Clone Story," in Simulacra and Simulation, trans. by Sheila Faria Glaser (University of Michigan Press, 1995), 95.

(c) 2021 Rhoderick V. Nuncio and Johannah Mari B. Felicilda https://www.kritike.org/journal/issue 29/nuncio\&felicilda december2021.pdf ISSN 1908-7330 


\section{CYBERNETICS AND SIMULACRA}

sophisticated than in our physical state. In fact, what is lacking in our physiological attributes can be visible in our digital self. It becomes therefore a realization of one's dream - to be beautiful, strong, and powerful. This imaginative reality of the digital self is the existential lack, the direct opposite of what and who we are in the real world. Thus, there is this aspiration to clone oneself or to have digital duplicate that is made possible in cyberreality.

This is what happens to us with cloning, no longer only at the level of messages, but at the level of individuals. In fact, this is what happens to the body when it ceases to be conceived as anything but a message, as a stockpile of information and of messages, as fodder for data processing .... There is a precession of reproduction over production, a precession of the genetic model over all possible bodies. It is the irruption of technology that controls this reversal, of a technology...in its total consequences, as a total medium... $.28^{28}$

This technology being referred here is the cybernetic nature of online games. It generates reproduction of digital selves interacting in multiplayer games. This is the code entering socialization. Interaction in the creative ecosystem as hyperreality contributes to cloning a "perfect" player to will for perfection. A player will never complete the game if his/her digital self does not possess those qualities of strength, wit, and endurance. The aesthetic projection is always positive and must aim toward perfection. Otherwise, a player loses the game. Online games as cybernetic constructs are competitive in nature. Dedicated players use whatever means necessary to advance faster and further than their competitors. In the case of Wizards Unite, inter-player interaction within the game is limited but there is an expansive story line and Skills Tree the player must unlock which requires lengthy hours of gameplay. To bypass the time and distance requirement of the game, a player may buy coins using real money. These coins could also be used to increase energy levels which would make replenishing it faster. Hence, the will for perfection is driven by consumption through the monetization of the game. In most of the games, purchasing gems or power icons is an absolute necessity to compete, win, and gain recognition.

\footnotetext{
${ }^{28}$ Ibid., 98.
}

(c) 2021 Rhoderick V. Nuncio and Johannah Mari B. Felicilda https://www.kritike.org/journal/issue 29/nuncio\&felicilda december2021.pdf ISSN 1908-7330 


\section{Feedback Loop and Evolution of the Game}

To keep the interest of their patrons, the developers periodically update the game to fix bug issues, offer seasonal challenges, extend the story line, and add new Foundables and adversaries. These updates provide more avenues for the player to advance in the game. For example, they host Community Days in which there are special tasks and rewards to encourage players to play during synchronously. There are also highlight events that focus on a specific type of Foundable or a specific point in the story line. Upgrades and updates in the game are quite limited as well. There are no new skills to be unlocked or potions to be made. There are only new tasks to be accomplished and Foundables to be collected. There are also hardly any changes in gameplay which eventually made users lose interest in the game.

The game has sufficiently replicated the Wizarding World of J.K. Rowling; however, it still leaves much to be desired. As was stated before, AR gaming relies more on the users for the completion of the experience rather than its technological prowess. The graphics of the game are well illustrated but the "magic" truly happens in the imagination of the user. For someone who has in-depth knowledge of the Harry Potter series, you would find yourself drawing from memory to elevate the experience of playing the game. Much of what motivates players to continue playing the game, despite its tiring gameplay, is nostalgia. Therefore, it is the users' imagination aided by the virtual world of the game and driven by nostalgia that completes the gaming experience and immerses the player further into the game. However, considering that the game offers a different storyline and setting than what their target demographic was expecting, they failed to sustain the hype of the game. This resulted in its impending closure. The game will no longer be offered by the end of January 2022. Part of the demise of the game is that there is hardly any improvements or changes in the actual gameplay; every update was more of the same thing. There was limited interaction between players despite the clamor for the inclusion of a Dueling aspect. Because of this, the motivation and interest of the user eventually wavered because there is no one to share the experience with. For creative ecosystems to thrive, the components must continuously interact and evolve. In the context of AR games, the player is the most important component because the virtual world of the game expands every gaming session. If the player is not satisfied with how the game is developed and eventually stops playing, the creative ecosystem of the game dies. This shows that the human aspect in a cybernetic relationship trumps the technological dimension no matter how advanced the latter is.

The very nature of online games is contingent as commodity-sign. It is a signification that has no fixed signifier and signified unlike in other

(c) 2021 Rhoderick V. Nuncio and Johannah Mari B. Felicilda

https://www.kritike.org/journal/issue 29/nuncio\&felicilda december2021.pdf

ISSN 1908-7330

(cc) BY-NC-ND 


\section{CYBERNETICS AND SIMULACRA}

commodities. Material products are tangible and accessible as long as these are available in the market. Once the products are out-of-stock, manufacturers can reproduce and resell it continuously for public consumption. The underlying rationale is production based on human needs. Products have use-value and exchange-value intact upon production and consumption. Thus, for example, if we purchase a bicycle it is based on our practical need to use it for transportation. Its exchange value is the price we need to pay in order to acquire it. For Baudrillard, this is reversed:

The point is that...the consumption of a commodity in general, is not consumption based upon a need, which in Marx is formalized as the Use-value. It is a consumption of what it signifies and how the consumer consuming the sign is integrated within the system. This is why, in the anticipation of communication as an important perspective in analyzing society, Baudrillard necessitates this inversal of priority, from the original conception of Marx on production to consumption. ${ }^{29}$

This inversion of consumption over production is necessary for us to place the intangibility of commodity-sign as the reason why online games are exhaustible yet reproducible endlessly within the economic loop of digital capitalism. For Baudrillard, the sign-value or the commodity-sign reverses or reduces use-value. We consume something not on a basis of need but because of the superimposing ideology ${ }^{30}$ of the times - the rise of digital capitalism. We are then forced to accept and obey how history and society are being transformed toward this direction. This new system albeit coexisting with modern capitalism is the ideological code for the profusion and proliferation of various digital commodities in the real world.

\section{Rise of Digital Capitalism: Society of Hyperreality}

Baudrillard may have predicted the rise of advanced capitalism that is grounded on his theory of the simulacra. At the outset, there are devices or gadgets that make possible the reproduction of simulacrum or hyperreality. The internet for example is an inter-networking of computers and servers around the globe that gave birth to cyberspace. Likewise, through our personal computers or smartphones which are connected via the internet, multitudes of virtual operations give rise to a new reality - an "electronic"

29 Daryl Y. Mendoza, “Commodity, Sign, and Spectacle: Retracing Baudrillard's Hyperreality," in Kritike, 4 (2010), 49.

${ }^{30} \mathrm{Ibid} ., 52$.

(c) 2021 Rhoderick V. Nuncio and Johannah Mari B. Felicilda

https://www.kritike.org/journal/issue 29/nuncio\&felicilda december2021.pdf

ISSN 1908-7330

(c) BY-NC-ND 
reality. Throughout the emergence of computing technology, the internet and information society, the disruptive arrival and rise of e-commerce, e-learning, e-sports, online banking, online gaming, social media, cloud computing, video streaming, and bitcoin have captivated multitudes of digital consumers who usher in a new world order. These technological breakthroughs in a way augment the very fabric of societal processes and human development. We can therefore say that we are living in the age of AR as hyperreality itself. ${ }^{31}$

In its contextual definition within online gaming parlance as explained in the preliminary part of the paper, AR refers to "a system that enhances the real world by superimposing computer-generated information on top of it." 32 As such, to proceed philosophically, we shall decontextualize the concept of AR then recontextualize it within the immanent and transcendent significations initially laid out in the preceding part. First, let's dissociate the two terms "augmented" and "reality." Etymologically, the word "augmented" or "augment" comes from the Latin term augere which means "to increase, make big, enlarge, enrich." Reality in this case is a complex and complicated concept in philosophy but for etymological purposes, the root word "real" comes from the Latin term realis which means actual and from old French reel as real and actual. Thus, in our context, reality is that which something that exists empirically and physically. This means that reality refers to objects and entities that are apprehended by our senseperception (hedonistically) and to a larger extent the dissipation of abstractions and criticality that are contemplated through and by pure thought (nihilistically). In this respect, it should be noted that what we are referring here as reality is the "material world," which has a Marxist overtone as this shall be elaborated in the succeeding section. Thus, if we philosophize the use of AR semantically, it means an enlarged and enriched version of our material world through information and communication technologies. This augmented version is not simply and should not be taken as relating to magnify or deepen our existential experiences with our reality but rather provides a paradigm that veers away from it. Enlarged version of the material world is inculcating in our minds the globality of technological experience through the internet and digital platforms. Such buzzwords as borderless world, information superhighway, network society, globalization, and the like have depicted a world larger than our locality and identity. Heralding cosmopolitanism and global citizenship becomes the norm spread nowadays.

31 This reverberates a proclamation that we live now in hyperreality. See Kian Bakhtiari, "Welcome To Hyperreality: Where The Physical And Virtual Worlds Converge," in Forbes (30 December 2020), <https://www.forbes.com/sites/kianbakhtiari/2021/12/30/welcome-tohyperreality-where-the-physical-and-virtual-worlds-converge/?sh=61e57f665028>.

32 "Augmented Reality," in Encyclopedia of Multimedia, ed. by Borko Furht (Boston: Springer, 2006), <https://link.springer.com/referenceworkentry/10.1007\%2F0-387-30038-4_10>.

(c) 2021 Rhoderick V. Nuncio and Johannah Mari B. Felicilda https://www.kritike.org/journal/issue 29/nuncio\&felicilda december2021.pdf ISSN 1908-7330 


\section{CYBERNETICS AND SIMULACRA}

Furthermore, enriched version of the material world expounds these focal exaggerations as a way of saturating our visual field with commodities, signs, and simulations while we gaze upon big traditional and digital billboards around the city and while we engage contents in our smartphones with popups of video and graphic advertisements. AR therefore is a superimposed worldview of social relations on the way we think, live, behave, exist in this contemporary world. Altogether, as Baudrillard argues, we are surrounded by simulations and simulacra as the defining moments of our time.

However, it should be clearly underscored here that digital capitalism, though, reproduces a system of commodified signs still rests on material capitalism. There is a split capitalism similar to a split location of player/being within a social/digital continuum. To better comprehend this, let us use an analogy. On one hand, an immanent critique tries to situate AR games in the intricacies of a dual location - that is, a split recognition that there exists a real and digital environment. The split is a bilocation pertaining to the position of "being" both in his natural/physical/social world and in cyberspace. This being as shown in the descriptive analysis of Wizards Unite is the online gamer/player. AR in this context internalizes the possibility and cogency of a cybernetic (or symbiotic) relationship of beings and machines. The meeting point of this duality is the endless or infinite consummation and consumption of the game itself. On the other hand, AR as a transcendent signification encompasses a macrocosmic view that our contemporary conditions must be seen in the light of a dual capitalism. The first one is what we typically associate with "modern capitalism" whereas the second type is what many triumphantly calls as "digital capitalism." AR in this critical postulation externalizes the legitimacy of "digital reality," a new metaphysics that foregrounds the rise of Fourth Industrial Revolution (4IR). Cybernetics here takes a new level when a social-digital being is referred to as "cyborg" and that our sense of apprehending reality is encumbered by a new attempt toward a singularity. Each of the digital breakthrough is governed by a capitalistic "ecosystem" because the very foundation of its ontology is an extension of a capitalist neoliberal economic structure. ${ }^{33}$ Frederick Jameson recognizes that:

Technology is, however, on the Marxist view the result of the development of capital, rather than some primal cause in its own right. It will therefore be appropriate to distinguish several generations of machine power,

${ }_{33}$ See Jens Schröter, "The Internet and 'Frictionless Capitalism'," in Marx in the Age of Digital Capitalism, ed. by Christian Fuchs and Vincent Mosco (Leiden: Brill), 134.

(c) 2021 Rhoderick V. Nuncio and Johannah Mari B. Felicilda https://www.kritike.org/journal/issue 29/nuncio\&felicilda december2021.pdf ISSN 1908-7330

(c) BY-NC-ND 
several stages of technological revolution within capital itself. ${ }^{34}$

It must be systemic and systematic with the rise of 4IR, in which with the popularity of the term Internet of Things, or IoT, it describes the relationship between things (products, services, places, etc.) and people that is made possible by connected technologies and various platforms. ${ }^{35}$ As this technological worldview becomes dominant the emergence of new terminologies such as artificial intelligence, ${ }^{36}$ machine learning, ${ }^{37}$ and computer vision ${ }^{38}$ that together shape and influence how people interact with digital platforms, computer systems, and internet technologies is becoming apparent. The end goal is to make humans and their various ways of life interconnected with the machine and the internet. Furthermore, these complex interactions underpin a Marxist critique, which articulates that:

"...neither the conditions of production nor the forces of production can be considered the individual cause; rather, the cause is always to be found in their complex interaction. Thus "transnational business," the growing trend to outsource whole sections of companies, was accelerated or indeed only made possible by the net, itself increasingly incorporated into hegemonic capitalist discourse." 39

${ }^{34}$ Frederick Jameson, Postmodernism or the Logic of Late Capitalism (Durham: Duke University Press, 1991).

${ }^{35}$ Klaus Schwab, The Fourth Industrial Revolution (Geneva: World Economic Forum, 2016), 22.

${ }^{36}$ Artificial intelligence (AI) refers to the simulation of human intelligence in machines that are programmed to think like humans and mimic their actions. The term may also be applied to any machine that exhibits traits associated with a human mind such as learning and problemsolving. Jake Frankenfield, "How Artificial Intelligence Works," in Investopedia, accessed 17 March 2021, <https://www.investopedia.com/terms/a/artificial-intelligence-ai.asp>.

${ }_{37}$ Machine learning is a method of data analysis that automates analytical model building. It is a branch of artificial intelligence based on the idea that systems can learn from data, identify patterns and make decisions with minimal human intervention. "Machine Learning: What It Is and Why It Matters," accessed 17 March 2021, $<$ https://www.sas.com/en_ph/insights/analytics/machine-learning.html>.

${ }^{38}$ Computer vision is a field of artificial intelligence that trains computers to interpret and understand the visual world. Using digital images from cameras and videos and deep learning models, machines can accurately identify and classify objects - and then react to what they "see." See "Computer Vision: What It Is and Why It Matters," accessed 17 March 2021, $<$ https://www.sas.com/en_ph/insights/analytics/computer-vision.html>.

${ }^{39}$ Schröter, "The Internet and 'Frictionless Capitalism'," 164.

(c) 2021 Rhoderick V. Nuncio and Johannah Mari B. Felicilda

https://www.kritike.org/journal/issue 29/nuncio\&felicilda december2021.pdf

ISSN 1908-7330

(cc) BY-NC-ND 


\section{CYBERNETICS AND SIMULACRA}

The economic base is the same as Marx pointed out in his critique of capitalism, which refers to the overarching economic structure of society, when we speak of the contemporary state of play that we have in the age of 4IR. This pre-eminence of 4IR is the era of postcapitalism, virtual capitalism, or digital capitalism. The mode of production and the economic ruling class has just expanded the meaning of property and capital by including all that are associated with the kinds of business model that are apparent in Google, Amazon, and other Silicon Valley multinational tech companies wherein commodities are now labelled as software, applications, solutions, or information that people subscribe to and therefore own given a limited time of use. These include downloadable online games, Microsoft's Office suite, Google's cloud storage, and the like as the new products, virtual objects, in the complex system of digital capitalism. Most of the applications are free like online shopping apps Shopee or Amazon but these e-commerce platforms make it possible to transact and pay for goods and services via online.

Let us dissect this hegemonic structure of late capitalist tendencies immanent in digital capitalism. Jameson presents two major characteristics of this systemic phenomenon: the rise of transnational companies and the prevalence of uncritical acceptance. In the first characteristic, Jameson underpins a borderless economy that is not governed or ran by nation-states but rather extends beyond these boundaries. As mentioned above, he avoids the notion that technology predetermines the state of affairs:

As I have said, however, I want to avoid the implication that technology is in any way the 'ultimately determining instance' either of our present-day social life or of our cultural production: such a thesis is of course ultimately at one with the post-Marxist notion of a 'postindustrialist' society. Rather, I want to suggest that our faulty representations of some immense communicational and computer network are themselves but a distorted figuration of something even deeper, namely the whole world system of present-day multinational capitalism. ${ }^{40}$

This proclivity towards creating a virtual version of all our societal and social institutions and interactions is anchored on the imbalance of multilayered forces-owners, producers, commodities, labor, and consumers - in a global society. The imbalance is deliberate and intentional as this mirrors class division and stratification to regenerate capital in favor of the ruling

40 Jameson, Postmodernism, 79.

(c) 2021 Rhoderick V. Nuncio and Johannah Mari B. Felicilda https://www.kritike.org/journal/issue 29/nuncio\&felicilda december2021.pdf ISSN 1908-7330

(c) BY-NC-ND 
class (owners and producers of technology) and the commodification of all our digital interactions. Case at point here is the staggering economic power of the online gaming industry, which generated $\$ 175.8$ billion in 2021 and is expected to increase by $\$ 200$ billion in 2023.41 This is just one segment of the digital economy, in which the owners of production are predominantly based in the US and China according to the UN Digital Economy Report in 2019.42 Since digital economy is borderless and distributed globally through outsourcing and communication networks using the internet, class division and stratification is transposed and redistributed as cheap labor in developing countries in which, for example, workers in Vietnam or the Philippines assemble the parts and pieces of electronic hardware of smartphones or computer motherboards. We can also identify freelancers posing as tech savvy programmers or graphic designers, Millennials and the Generation $\mathrm{Z}$ as online gamers. This permutation of identity categories is fluid and indeterminate as this group of persons could be one and different at the same time when we refer to specific digital activities. However, the main point to consider is that they are caged in a complex digital ecosystem, in which the cyclical and teleological aim is sustained consumption and the commodification of being.

So one might be tempted to think of capital and capitalist economy like a machine that can be controlled calculatively, just like a technological cybernetic system. In this case, the essence of capital would correspond entirely to the productive, calculative, controlling essence of technology that sets up the totality of beings as a standing reserve for endless circuits of production, and the political polemic against the machine-like 'capitalist system' would have some justification. ${ }^{43}$

For the second characteristic, Jameson reiterates that there is a consensual jubilation regarding the advent of a new cultural logic of postmodernism (hitherto as digital age) with

\footnotetext{
${ }^{41}$ Frank Palermo, "Time To Get Your Game On: The Future Of Online Gaming," in Forbes (20 July 2021), <https://www.forbes.com/sites/forbestechcouncil/2021/07/20/time-toget-your-game-on-the-future-of-online-gaming/?sh=1f856e03705e $>$.

42 United Nations Conference on Trade and Development, UN Digital Economy Report in 2019 (2019), <https://unctad.org/webflyer/digital-economy-report-2019>.

43 Michael Eldred, The Digital Cast of Being: Metaphysics, Mathematics, Cartesianism, Cybernetics, Capitalism, Communication (Frankfurt: Ontos Verlag, 2011), 98-99.

(c) 2021 Rhoderick V. Nuncio and Johannah Mari B. Felicilda https://www.kritike.org/journal/issue 29/nuncio\&felicilda december2021.pdf ISSN 1908-7330 


\title{
62 CYBERNETICS AND SIMULACRA
}

\begin{abstract}
the complacent (yet delirious) camp-following celebration of this aesthetic new world (including its social and economic dimension, greeted with equal enthusiasm under the slogan of "post-industrial society") is surely unacceptable-although it may be somewhat less obvious the degree to which current fantasies about the salvational nature of high technology, from chips to robots - fantasies entertained not only by left as well as right governments in distress, but also by many intellectuals. ${ }^{4}$
\end{abstract}

Within the context of digital divide, those who join the digital bandwagon because of their socioeconomic status or their deep-seated fascination or addiction to internet use regardless of class, race, or gender belong to the "digital haves" and those who could not afford or have the opportunity to access the internet are considered the "haves-not." Nonetheless, the manipulative tendency of digital capitalism with its ideological code pervasive to signify "advancement," "innovation," "digitalization" and the placement of individuals within the technosocial environment under the guise of digital literacy and technological development is to capacitate and lure the have-nots to be part of this ideological ecosystem - to be plugged into the machine, so to speak. To simplify this complex interplay is to accentuate the rise of digital capitalists as the controlling power while rendering as normative and passive or frictionless the rest of humanity as digital consumers.

\section{Conclusion: Dwelling In and Out of the Digital Cave}

The idea of AR or hyperreality can be explained using Plato's classical allegory of the cave, in which a dialogue between Socrates and Glaucon narrates the story of people living inside the cave. In a nutshell, what Socrates is saying is that to imagine this:

People live under the earth in a cavelike dwelling. Stretching a long way up toward the daylight is its entrance, toward which the entire cave is gathered. The people have been in this dwelling since childhood, shackled by the legs and neck. Thus they stay in the same place so that there is only one thing for them to look that: whatever they encounter in front of their faces. But

${ }^{44}$ Jameson, Postmodernism, 85.

(c) 2021 Rhoderick V. Nuncio and Johannah Mari B. Felicilda https://www.kritike.org/journal/issue 29/nuncio\&felicilda december2021.pdf ISSN 1908-7330

(c) $)$ BY-NC-ND 
because they are shackled, they are unable to turn their heads around. ${ }^{45}$

This thought experiment interpreted in many ways points out to Plato's epistemology and political philosophy. In concluding this paper let us try to imagine the cave as the digital cave, a bubble hyperreality wherein online games using AR technologies are made possible. Alfred North Whitehead once said that in sum all philosophy is a just a footnote to Plato. It is in this conjecture that we put together reinterpreting the idea of simulation in Plato's terms or more precisely in the allegorical cave's terms. The difference, however, is that we must consider imagining it in a reversed way.

Plato, it is said, opposed essence to appearance, the original to the image, the sun of truth to the shadows of the cave, and to overturn Platonism would initially seem to imply a reversal of this standard relation: what languishes below in Platonism must be put on top; the super-sensuous must be placed in the service of the sensuous. 46

Assuming that people are outside the cave in the realm of "reality," what if they are forced to enter a simulated domain in which we can resemble the allegorical cave as our digital cave? The people shackled are wired people connected to online games. The fire represents the internet, the platform that ignites and fuels the assemblages of images, text, symbols, sounds that we directly encounter on the screen (cave's wall). These assemblages are the shadow cast on the wall of the cave. And the people who make all forms of shadowy images that are projected on the wall are in comparison the designers and owners of technology who created the games that we play inside the digital cave.

Why are we compelled to dwell inside the digital cave? If by the original intent of Plato is to illustrate how education is necessarily good as against the lack of it, why then some of our young generation choose to be in this domain? The sweeping generalization to answer this question is because kids today are born into this digital reality. But a larger context is crucially apparent. The digital cave actually is much bigger than what we think. This is the realm of digital society wherein we are crossing into a new reality. And through this transit as it becomes inevitable is the ultimate aim going toward

\footnotetext{
45 Plato, Allegory of the Cave, trans. Thomas Sheehan. Available in $<$ https://web.stanford.edu/class/ihum40/cave.pdf $>$.

${ }^{46}$ Daniel W. Smith, "The Concept of the Simulacrum: Deleuze and the Overturning of Platonism," in Continental Philosophy Review, 38 (2005), 46.
}

(c) 2021 Rhoderick V. Nuncio and Johannah Mari B. Felicilda https://www.kritike.org/journal/issue 29/nuncio\&felicilda december2021.pdf ISSN 1908-7330 


\section{CYBERNETICS AND SIMULACRA}

the metaverse. Its meaning is not just an AR, rather, as defined by Merriam Webster, a "metaverse generally refers to the concept of a highly immersive virtual world where people gather to socialize, play, and work." There lies yet the unexpected and the anticipation of what would be this be. Baudrillard succinctly predicts and anticipates the arrival of this metaverse as virtual reality:

By crossing into a space whose curvature is no longer that of the real, nor that of truth, the era of simulation is inaugurated by a liquidation of all referentials - worse: with their artificial resurrection in the systems of signs, a material more malleable than meaning, in that it lends itself to all systems of equivalences, to all binary oppositions, to all combinatory algebra. It is no longer a question of imitation, nor duplication, nor even parody. It is a question of substituting the signs of the real for the real, that is to say of an operation of deterring every real process via its operational double, a programmatic, metastable, perfectly descriptive machine that offers all the signs of the real and shortcircuits all its vicissitudes ${ }^{47}$.

As philosophers we have the obligation to explicate the nature of this reality and we can only do so if we penetrate its interstices. We cannot critique from afar. In deconstructing this phenomenon an immanent and transcendent ruminations must be put in place. This paper has shown how we can do that by critically analyzing the hegemonic ubiquity of online games. A specific intertextual reading is made through an analysis of Harry Potter: Wizard Unite as an example of AR. The fundamental structure of this game is presented by imputing the idea of cybernetics within the lens of a creative ecosystem. Furthermore, the theoretical or philosophical underpinnings of such analyses are explained by adopting Baudrillard's concepts of the simulation and the simulacra. The reality that the game posits is hyperreality and it operates by exalting and deploying the commoditysigns of virtual objects (including the player as virtual character) in the game as part and parcel of the entire nexus of relations. The narrative code leads us to the consumption and consummation of the game. Towards the end of the critical analysis, an ideological code is extracted to view that playing the game is not an end in itself. It is connected to a bigger complex of social reality enshrined in the logic and rhetoric of modern and digital capitalism. As

\footnotetext{
${ }^{47}$ Jean Baudrillard, "Precession of Simulacra," in Simulacra and Simulation, trans. Sheila Fayer Glaser (Ann Arbor: University of Michigan Press, 1995), 3-4.

(c) 2021 Rhoderick V. Nuncio and Johannah Mari B. Felicilda https://www.kritike.org/journal/issue 29/nuncio\&felicilda december2021.pdf ISSN 1908-7330
}

(c) BY-NC-ND 
argued earlier in this paper, digital capitalism, which is the overarching context of this era, makes it possible to lump altogether humans, goods, and services to feign a whole system of our social, cultural, and economic interactions interoperable through and by technological infrastructure. No escape! Though it may sound self-defeating, the simulations and simulacra of our reality is just evolving and philosophy as criticism should be "[g]enuine criticism [that] will then reveal the human reality beneath this general unreality, the human 'world' which takes shape within us and around us: in what we see and what we do, in humble objects and (apparently) humble and profound feelings." 48

Departamento ng Filipino, College of Liberal Arts De La Salle University-Taft, Philippines

\section{References}

"Augmented Reality," in Encyclopedia of Multimedia, ed. by Borko Furht (Boston: Springer, 2006), <https://link.springer.com/reference workentry/10.1007\%2F0-387-30038-4_10>.

Baudrillard, Jean, "Simulacra and Simulations," in Jean Baudrillard, Selected Writings, ed. by Mark Poster (California: Stanford University Press, 1988).

"System of Objects," in Jean Baudrillard, Selected Writings, ed. by Mark Poster (California: Stanford University Press, 1988).

"Clone Story," in Simulacra and Simulation, trans. by Sheila Faria Glaser (Ann Arbor: University of Michigan Press, 1995).

"Precession of Simulacra," in Simulacra and Simulation, trans. by Sheila Faria Glaser (Ann Arbor: University of Michigan Press, 1995).

Bakhtiari, Kian, "Welcome To Hyperreality: Where The Physical And Virtual Worlds Converge," in Forbes (30 December 2020), $<$ https://www.forbes.com/sites/kianbakhtiari/2021/12/30/welco me-to-hyperreality-where-the-physical-and-virtual-worldsconverge/?sh $=61 \mathrm{e} 57 \mathrm{f} 665028>$.

"Computer Vision: What It Is and Why It Matters," accessed 17 March 2021, $<$ https://www.sas.com/en_ph/insights/analytics/computervision.html>.

${ }^{48}$ Henri Lefebvre cited in Richard J. Lane, Jean Baudrillard, Routledge Critical Thinkers, (London: Routledge, 2000), 80.

(c) 2021 Rhoderick V. Nuncio and Johannah Mari B. Felicilda https://www.kritike.org/journal/issue 29/nuncio\&felicilda december2021.pdf ISSN 1908-7330 


\section{CYBERNETICS AND SIMULACRA}

Eldred, Michael, The Digital Cast of Being Metaphysics, Mathematics, Cartesianism, Cybernetics, Capitalism, Communication (Frankfurt: Ontos Verlag, 2011).

Frankenfield, Jake, "How Artificial Intelligence Works," in Investopedia, accessed 17 March 2021, $<$ https://www.investopedia.com/terms/a/artificial-intelligenceai.asp $>$.

Genesko, Gary, "Jean Baudrillard's Contributions to Semiotic and Structural Studies," in International Journal of Baudrillard Studies, 4 (2007).

Gibson, Eleanor, "Augmented-Reality Exhibition Launched to Sell Artwork during the Pandemic," in Dezeen (17 April 2020), $<$ https://www.dezeen.com/2020/04/17/all-show-augmentedreality-exhibition-sebastian-errazuriz/>.

Haraway, Donna, "A Cyborg Manifesto: Science, Technology, and SocialistFeminism in the Late Twentieth Century," in Simians, Cyborgs and Women: The Reinvention of Nature, 149-81 (New York: Routledge, 1991).

Hayles, Katherine, How We Became Posthuman: Virtual Bodies in Cybernetics, Literature, and Informatics (Chicago: University of Chicago Press, 1999).

Jameson, Fredric, Postmodernism, or the Cultural Logic of Late Capitalism (Durham: Duke University Press, 1991).

Kendall, Lori, "Meaning and Identity in 'Cyberspace': The Performance of Gender, Class, and Race Online," Symbolic Interaction, 21 (1998).

Lane, Richard, Jean Baudrillard (London: Routledge, 2000).

Lee, Chun-Hsiung, Hsiu-Sen Chiang, and Kuo-Lun Hsiao, "What Drives Stickiness in Location-Based AR Games? An Examination of Flow and Satisfaction," Telematics and Informatics, 35 (2018).

"Machine Learning: What It Is and Why It Matters," accessed 17 March 2021, $<$ https://www.sas.com/en_ph/insights/analytics/machinelearning.html>.

McCormack, Jon, "Creative Ecosystems," in Computers and Creativity, 51 (1998).

Mendoza, Daryl, “Commodity, Sign, and Spectacle: Retracing Baudrillard's Hyperreality," in Kritike, 4 (2010).

North of 41, "What Really Is the Difference between AR / MR / VR / XR?" in Medium (20 March 2018), $<$ https://medium.com/@northof41/what-really-is-the-differencebetween-ar-mr-vr-xr-35bed1da1a4e>.

Owen, David, "Cyber Narrative and the Gaming Cyborg," in Journal of Gaming \& Virtual Worlds, 6 (2014).

(c) 2021 Rhoderick V. Nuncio and Johannah Mari B. Felicilda https://www.kritike.org/journal/issue 29/nuncio\&felicilda december2021.pdf ISSN 1908-7330

(cc) BY-NC-ND 
Palermo, Frank, “Time To Get Your Game On: The Future Of Online Gaming," in Forbes (20 July 2021), $<$ https://www.forbes.com/sites/forbestechcouncil/2021/07/20/tim e-to-get-your-game-on-the-future-of-onlinegaming/?sh=1f856e03705e $>$.

Plato, Allegory of the Cave, trans. Thomas Sheehan. Available in $<$ https://web.stanford.edu/class/ihum40/cave.pdf $>$.

Schröter, Jen, "The Internet and 'Frictionless Capitalism'," in Marx in the Age of Digital Capitalism, ed. by Christian Fuchs and Vincent Mosco (Leiden: Brill, 2006).

Smith, Daniel, "The Concept of the Simulacrum: Deleuze and the Overturning of Platonism," in Continental Philosophy Review, 38 (2005).

Schwab, Klaus, The Fourth Industrial Revolution (Geneva: World Economic Forum, 2016).

Sheth, Jagdish, "Impact of Covid-19 on Consumer Behavior: Will the Old Habits Return or Die?," in Journal of Business Research, 117 (2020).

Shin, Donghee, "How Does Immersion Work in Augmented Reality Games? A User-Centric View of Immersion and Engagement," in Information, Communication \& Society, 22 (2019).

United Nations Conference on Trade and Development, UN Digital Economy Report in 2019 (2019), <https://unctad.org/webflyer/digitaleconomy-report-2019>/

Wiener, Norbert, Cybernetics: Or, Control and Communication in the Animal and the Machine, 2nd ed., (Cambridge: The MIT Press, 2019). 